\title{
Microgeographic Spatial Structuring of Triatoma infestans (Hemiptera: Reduviidae) Populations Using Wing Geometric Morphometry in the Argentine Chaco
}

\author{
M. S. GASPE ${ }^{1}$, J. SCHACHTER-BROIDE ${ }^{1}$, J. M. GUREVITZ ${ }^{1}$, U. KITRON² ${ }^{2}$ R. E. GÜRTLER ${ }^{1,3}$, \\ and J. P. DUJARDIN ${ }^{4}$ \\ ${ }^{1}$ Laboratorio de Eco-Epidemiología, Depto. de Ecología, Genética y Evolución, Facultad de \\ Ciencias Exactas y Naturales, Universidad de Buenos Aires, Ciudad Universitaria, 1428EHA \\ Buenos Aires, Argentina \\ ${ }^{2}$ Department of Environmental Studies, Emory University, Atlanta, GA 30322 \\ ${ }^{4}$ Unité Mixte de Recherche (UMR), Institutes de Recherches pour le Développment (IRD)-Centre \\ National de Recherche Scientifique (CNRS), F-34394 Montpellier, France
}

\section{Abstract}

We investigated the occurrence of spatial structuring in Triatoma infestans (Klug) (Hemiptera: Reduviidae) populations $12 \mathrm{yr}$ after the last community-wide insecticide spraying campaign in rural Pampa del Indio, in the Gran Chaco of northeastern Argentina. In total, 172 male and 149 female right wings collected at 16 georeferenced sites with at least 10 individuals of the same sex were analyzed using geometric morphometry. Mean female body length and wing centroid size (CS) were significantly larger than for males. Log-transformed CS and length were significantly and positively correlated both for males and females. Males collected in domiciles had significantly smaller CS than those collected in peridomestic structures both closed (kitchens or storerooms) or open (chicken coops), in agreement with our previous results elsewhere in the dry Argentine Chaco. Female wing CS was not significantly different between ecotopes. Wing shape analyses showed the occurrence of significant geographic structuring in males and females combined and in males only. Male wings showed a strong association between Mahalanobis distance and geographic distance. In general, Mahalanobis distances were significantly different between collection sites located $>4 \mathrm{~km}$ apart. For collection sites located $<4 \mathrm{~km}$ apart, the greater the geographic distance the larger the difference in wing shape variables. Among females, only a partial correspondence between geographic groups and Mahalanobis distances was recorded. The strong spatial structuring found in $T$. infestans populations may be useful for the identification of putative reinfestation sources after vector control interventions.

\section{Keywords}

Triatoma infestans; geometric morphometry; population structure; vector control; reinfestation

Chagas disease still remains a serious public health problem in Central and South America (WHO 2007). Triatoma infestans (Klug) (Hemiptera: Reduviidae) is the main vector of Trypanosoma cruzi Chagas in the Southern Cone countries, where it mainly occupies domestic and peridomestic ecotopes. A regional control program aiming at the elimination

(C) 2012 Entomological Society of America

${ }^{3}$ Corresponding author, gurtler@ege.fcen.uba.ar. 
of $T$. infestans dramatically reduced its geographic range and interrupted vector- and bloodborne transmission of T. cruzi in Uruguay, Chile, Brazil, and parts of Argentina and Paraguay (Dias et al. 2002, Schofield et al. 2006). However, in the Gran Chaco region of Argentina, Bolivia, and Paraguay, the effectiveness of vector control efforts was limited and vector-borne transmission of $T$. cruzi persists, albeit at lower levels (Gürtler et al. 2007, Gorla et al. 2009). One of the main obstacles for the elimination of T. infestans is the reinfestation of houses after residual insecticide spraying (Dujardin et al. 1997a, Gürtler et al. 2004, Cecere et al. 2006). A better understanding of vector population structure and dispersal dynamics may help explain why vector control actions were less effective in the Gran Chaco, and contribute to the selection of appropriate vector control strategies.

Population-structure studies analyze whether isolated subpopulations exist within the apparently continuous distribution of a species. Genetic and/or phenetic markers have been used to study the patterns of spatial structuring among vectors of Chagas disease (Abrahan et al. 2008, Pérez de Rosas et al. 2008), malaria (Brochero et al. 2010), dengue (Scarpassa et al. 2008), leishmaniasis (de Queiroz Balbino et al. 2006), and African trypanosomiasis (Bouyer et al. 2007). Morphometric techniques are based on empirical evidence showing greater similarity between parental lines and their offspring than between nonrelated individuals (Dujardin et al. 1997b, 2007; Dujardin and Slice 2007). Wing shape analyses were used to assess spatial structuring in several triatomine species (Gumiel et al. 2003, Schachter-Broide et al. 2004, Dumonteil et al. 2007, Hernández et al. 2010) and other insect vectors (Dujardin et al. 2003, Camara et al. 2006, Bouyer et al. 2007). This information may be used to guide vector control strategies and has important economic consequences, as in the case of control decisions related to the elimination of the tsetse fly Glossina palpalis gambiensis Vanderplank in some African regions (Bouyer et al. 2007, Solano et al. 2010). For the major vector $T$. infestans, no study has addressed the spatial structuring of domestic and peridomestic bug populations in a well-defined endemic area where no official vector control interventions had been conducted for a substantial period of time.

As part of a multi-site research project on the eco-epidemiology and control of Chagas disease in the Gran Chaco region including sister sites in Bolivia and Paraguay, we sought to determine the occurrence of spatial structuring in T. infestans populations at a micro- and mesoscale using wing geometric morphometry in a well-defined endemic area in the Argentine Chaco where no systematic vector control actions had been conducted during the previous $12 \mathrm{yr}$. We will also use geometric morphometry to describe wing size differences among ecotopes. Future studies will use this information to address whether the insects collected after insecticide spraying were survivors from the insecticide treatment or immigrants from elsewhere.

\section{Materials and Methods}

\section{Study Area}

Fieldwork was conducted in Pampa del Indio ( $\left.25^{\circ} 55^{\prime} \mathrm{S} 56^{\circ} 58^{\prime} \mathrm{W}\right)$, Chaco Province, northeastern Argentina, located on the transition between the humid and dry Chaco region (Fig. 1). The study area included 353 houses and public buildings grouped in 13 rural villages located 10-45 km from Pampa del Indio town (Gurevitz et al. 2011). The district was last treated with residual insecticides by vector control programs in 1996. Most domiciles are mud-and-thatch huts with roofs of metal or tarred-cardboard sheets, occasionally with bricked walls plastered with cement. The two main ethnic groups are Creole and Toba. 


\section{The Insects}

A demographic and entomological survey of all houses and associated peridomestic structures was carried out in October through November 2007, immediately before community-wide spraying of all houses with pyrethroid insecticides. All domestic and peridomestic structures within the area were geo-referenced and inspected for triatomine infestation by skilled bug collectors from the Provincial Vector Control Program using timed manual collections with a dislodging spray. T. infestans was collected in $45.9 \%$ of the 327 inhabited houses; domiciles, kitchens, storerooms, and chicken coops and nests were the most frequently infested ecotopes (Gurevitz et al. 2011). Insects were identified to species and stage, weighed, and measured from the clypeus to the abdominal tip using a digital caliper (for body length, L) at the field laboratory on the day of collection.

Collection sites with at least 10 adult $T$. infestans of the same sex were selected for wing geometric morphometry analysis. Among collection sites with more abundant bug populations, a random sample of 15 adult bugs per site was chosen to achieve balanced sample sizes. In total, 172 males collected from 13 sites in eight villages and 149 females from 12 sites in nine villages were analyzed by wing geometric morphometry. Bugs were grouped by main collection habitats that reflected their different physical structure and microenvironmental conditions (Vazquez-Prokopec et al. 2002): domestic sites (human habitations) (males $=42$; females $=62$ ), closed peridomestic sites (including peridomestic structures protected from weather agents, such as kitchens and storerooms) (males $=50$; females $=41$ ), and open peridomestic structures (including more exposed peridomestic structures such as chicken coops and other structures associated with chickens) (males $=80$; females $=46$ ).

Among collection sites included in the sample, we selected those with individuals of both sexes to perform a pooled analysis. In total, 121 males and 115 females collected in nine sites were analyzed ( $n=21-30$ per site).

\section{Metric Data}

The wings were mounted between microscope slides and cover-slips as described in Schachter-Broide et al. (2004). Photographs of each pair of wings were taken using a digital camera (Sony MVC-CD300, Sony, Oradell, NJ) and a stereo-microscope (Zeiss SV11, Jena, Thuringia, Germany). We used the 10 type-1 landmarks (vein intersections) identified for $T$. infestans wings, according to Book-stein (1990). The position of each landmark was described elsewhere (Schachter-Broide et al. 2004, 2009). Only right wings were included in the analyses to avoid eventual pseudoreplication.

\section{Size Variation}

For comparison of wing size between groups, we used the isometric estimator known as centroid size (CS) derived from coordinates data. CS is defined as the square root of the sum of the squared distances between the center of the configuration of landmarks and each individual landmark (Bookstein 1990). Among the individuals included in the sample, data on body $\mathrm{L}$ and weight were available for 120 males and 128 females.

\section{Shape Variation}

Shape variables (partial warps, PW) were obtained using the Generalized Procrustes Analysis superimposition algorithm (Rohlf 1996). PW were computed first by pooling male and female data and then separately for each sex. To avoid having small sample sizes relative to the number of variables, we used a restrictive representation of shape (i.e., a set of principal components known as relative warps) derived from the shape variables. In all cases we explained $>90 \%$ of total shape variation. Residual allometry was estimated by 
multivariate regression of PW on size (Good 2000). Mahalanobis distances were derived from the selected set of (first) relative warps and then used to construct an unweighted pairgroup method with arithmetic average dendrogram using the Neighbor module of the Phylip package (Felsenstein 2005). These distances were also used to perform a simple reclassification test for each individual. The percentage of correctly assigned males and females to the corresponding geographic group was assessed.

\section{Data Analysis}

After checking that assumptions for parametric analyses were satisfied, L and wing CS were compared between sexes using one-way analysis of variance (ANOVA). This test was also used for examining CS differences between main ecotopes; a Tukey's test was also performed. Pearson correlation coefficients between individual log-transformed CS and logL were estimated using Stata 10.1 (StatCorp 2008). The statistical significance of multivariate regression of PW on CS was estimated by permutation tests using 1,000 runs (Good 2000). The statistical significance of Mahalanobis distance was computed by nonparametric permutation test (1,000 runs) and adjusted according to the Bonferroni procedure. The isolation-by-distance (IBD) model for each sex was tested by regressing Mahalanobis distance on geographic distances between collection sites; significance levels were determined by Mantel tests (1,000 permutations) using the module IBD (Bohonak 2002).

\section{Software}

For morphometric analysis we used TPSdig2 (version 2.09) for landmark digitalization; $M O G$ for Procrustes superimposition and generation of CS, PW, and RW; PAD for discriminant analyses, nonparametric permutation tests, and reclassification tests; PHYLIP (version3.5c.) and njplot (version1.6.6.) for unweighted pair-group method with arithmetic average tree construction. TpsDig2 (developed by F.J.R.) is available at www.life.bio.sunysb/morpho. The modules $M O G$ and $P A D$ developed by J.P.D. are included in the CLIC package available at www.mpl.ird.fr/morphometrics.

\section{Results}

Size

Mean female body $\mathrm{L}(25.95 \mathrm{~mm}, \mathrm{SD}=0.81 \mathrm{~mm})$ and wing $\mathrm{CS}(755.18, \mathrm{SD}=30.42)$ were significantly larger than male $\mathrm{L}(24.44 \mathrm{~mm}, \mathrm{SD}=0.66 \mathrm{~mm})$ and $\mathrm{CS}(725.71, \mathrm{SD}=27.45)$, respectively (L: $F=264.65, \mathrm{df}=1, P<0.0001$; $\mathrm{CS}: F=83.23$, df $=1, P<0.0001$ ). Therefore, male and female data were treated separately. Log-transformed CS and L were significantly and positively correlated in males (adjusted $R^{2}=0.46 ; P<0.0001$ ) and females (adjusted $R^{2}=0.38, P<0.0001$; Fig. 2).

Male bugs collected in domiciles had significantly smaller wing CS than those from chicken coops and kitchens or storerooms (Tukey's test; $F=4.85$; df $=1 P<0.001 ; P<0.03$, respectively), whereas males from different peridomestic sites had similar CS (Tukey's test, $F=4.85, \mathrm{df}=1, P>0.5$; Fig. 3A). Nonsignificant differences were found in wing CS of females collected in different ecotopes ( $F=0.44$, df $=2, P>0.5$; Fig. $3 \mathrm{~B})$.

\section{Shape}

For males and females pooled together, two groups including three and four collection sites each presented no significant differences in Mahalanobis distances $(P>0.001)$, whereas significant differences were found between collection sites from different groups. A significant correlation between Mahalanobis and geographic distances was found (Mantel 
test; $r=0.398 ; P<0.02)$. No significant residual allometric effect was found, suggesting that the differences observed were not because of size differences.

For male wings, a significant correlation between Mahalanobis distance and geographic distance was recorded (Mantel test, $r=0.311, P<0.02$; Fig. 4A). In general, Mahalanobis distances were significantly different between collection sites located $>4 \mathrm{~km}$ apart $(P<$ 0.001 ). For collections sites located $<4 \mathrm{~km}$ apart, the greater the geographic distance the larger the difference in shape variables. A high correspondence was found between the way several collection sites $(9 / 13=70 \%)$ were grouped in the unweighted pair-group method with arithmetic average dendrogram and geographic groups (Fig. 5). However, in a few bug collection sites male shape variables were not significantly different from any other collection site included in the analysis. Moreover, bugs from three pairs of houses geographically close to each other (1.4-2.9 km) had a significant divergence in Mahalanobis distances. When the occurrence of allometric effects was examined in the whole sample by regressing the first canonical factor of the discriminant analysis (DA) on wing CS, no significant residual allometry was found. Therefore, the observed differences in shape variables were not because of size effects.

For female $T$. infestans, wing shape analyses showed no significant association between Mahalanobis distance and geographic distance (Mantel test, $r=0.135, P>0.1$; Fig. 4B). Almost every Mahalanobis distance resulted nonsignificant. However, the unweighted pairgroup method with arithmetic average dendrogram showed two groups that coincided with geographic groups, suggesting a weak association between both metrics (Fig. 6). Moreover, simple reclassification scores to the two geographic groups were on average higher than $60 \%$ for males $(62-72 \%)$, females $(65-73 \%)$, and when both sexes were pooled in a single sample (65-71\%), supporting the observed differentiation between samples. This pattern, showing strong spatial structuring in males and a weaker association in female populations, was robust to the number of collection sites included in the analyses; the same qualitative results initially obtained with five collection sites (data not shown) were later confirmed when we included 16 study sites. These analyses were also performed after combining wing size and wing shape variables but the classifications did not improve relative to previous results (data not shown). Therefore, the analyses were performed with wing shape variables only.

\section{Discussion}

Our study has two main axes: wing shape and wing size variations in $T$. infestans populations at a micro-and mesoscale. The results of the wing shape analyses show the occurrence of spatial structuring in $T$. infestans populations located at distances ranging from 1.4 to $13.5 \mathrm{~km}$ (mean, $6.8 \mathrm{~km}$ ). The strong spatial structuring found by pooling male and female data and especially in male populations was unexpected given the absence of official vector control interventions during the previous $12 \mathrm{yr}$. In such context we expected that the bug populations would be at equilibrium with weak or no spatial structuring. This expectation was mostly based on findings showing that $T$. infestans populations from rural communities that had not been treated with insecticides during at least the last $9 \mathrm{yr}$ had less genetic differentiation (assessed by microsatellite markers) than populations that had recently been treated with insecticides in Catamarca Province, Argentina (Pérez de Rosas et al. 2007). A possible explanation for such differences between observed and expected patterns is that householders may have applied insecticides more frequently than what they reported during the intervening period between the last spraying campaign and our survey. This would also explain that $46 \%$ of all houses (most of them susceptible to triatomine colonization) were infested at the baseline survey (Gurevitz et al. 2011), whereas in other 
rural areas in the Chaco house infestations would have climbed up to $80 \%$ in less than $5 \mathrm{yr}$ after community-wide intervention (Gürtler et al. 2007).

The occurrence of spatial structuring has been studied in different triatomine species at different scales and using different markers (Monroy et al. 2003, Dumonteil et al. 2007, Pizarro et al. 2008). In T. infestans, most phenetic and genetic studies showed the occurrence of spatial structuring at a macrogeographic scale (Dujardin et al. 1998; Bargues et al. 2006; Pérez de Rosas et al. 2007, 2008; Piccinali et al. 2009; Hernández et al. 2010). The few studies that analyzed geographically proximate populations reported widely variable results. In Bolivia, populations located a few kilometers apart had significantly different gene frequencies in the Yungas tropical forest (Brenière et al. 1998, Dujardin et al. 1998), whereas no differences were found between collection sites located <20 km apart in the Cochabamba valleys (Dujardin et al. 1987) or $<50 \mathrm{~km}$ in Vallegrande (Dujardin et al. 1998). Most studies that reported strong spatial structuring at a microgeographic scale in $T$. infestans populations were performed in the context of recent community-wide or selective residual spraying with insecticides in Argentina (Schachter-Broide et al. 2004; Pérez de Rosas et al. 2007, 2008; Marcet et al. 2008), unlike our current study. Domestic bug populations under vector control actions are subjected to repeated bottleneck events that may result in local differentiation by genetic drift and higher gene flow restrictions than among untreated bug populations (Pérez de Rosas et al. 2007, Marcet et al. 2008). Both the spatial scale and the particular vector control history are important variables to consider in population structure studies, especially when making comparisons.

Our study shows a significant fit of the spatial distribution of $T$. infestans populations to the IBD model using wing geometric morphometry. Mahalanobis and geographic distances were significantly and positively associated both when males and females were pooled and in males only, supporting the qualitative results shown in the dendrograms. For male collection sites located $<4 \mathrm{~km}$ apart no significant differences were found in Mahalanobis distances. However, the greater the geographic distance between collection sites the greater the differentiation in wing shape variables. $T$. infestans males from three pairs of houses did not fit this general trend, as they presented a significant divergence in Mahalanobis distances despite the small geographic distance between them $(1.4-2.9 \mathrm{~km})$. These three pairs of houses were separated by patches of dense forest that may have acted as natural barriers to flight dispersal. Only a partial correspondence between Mahalanobis distances and geographic groups was found for females, suggesting a weak spatial structuring. However, high reclassification scores to the geographic groups were obtained for males and females. Moreover, almost the same collection sites were grouped together within males, females, and the whole sample, supporting the existence of a pattern of spatial structuring in these populations. Previous studies revealed different patterns regarding the IBD model in $T$. infestans populations. A positive correlation between genetic and geographic distances was found in bug populations from several areas of Bolivia and Peru using allozymes (Brenière et al. 1998, Dujardin et al. 1998), and in Argentina using microsatellite markers (Pérez de Rosas et al. 2008) and mitochondrial DNA (Piccinali et al. 2009). Using microsatellite markers at a micro-and mesoscale $(<30 \mathrm{~km})$, genetic distance did not correlate well with geographic distance in northwestern Argentina (Marcet et al. 2008) and Bolivia (Richer et al. 2007, Pizarro et al. 2008). Studies combining genetic and phenetic markers may improve the description of these spatial patterns because of the different spatial resolution of each marker. An important initial step in such studies is the selection of populations to be compared and their sample sizes, in relation to the marker used.

The weaker spatial structuring patterns observed in females than in males may be explained by a sex differential in flight dispersal capabilities. Female $T$. infestans initiated flight much more frequently than males (Lehane and Schofield 1982, Gurevitz et al. 2006) and also had 
substantially larger flight muscle mass (Gurevitz et al. 2007). Therefore, females may perform longer flights than males and have a greater flight range. Flight dispersal studies showed that T. infestans may fly at least $1.5 \mathrm{~km}$ in an open field (Schweigmann et al. 1988, Schofield et al. 1992), and $>2.4 \mathrm{~km}$ under laboratory conditions (Ward and Baker 1982). Moreover, modeling results suggest that the distance and intensity of dispersal in $T$. infestans varies seasonally, with a considerable proportion of bugs dispersing farther than $1.5 \mathrm{~km}$ in May-November (zu Dohna et al. 2009). Field observations showed the walking dispersal capabilities of $T$. infestans nymphs and adults collected around goat corrals and chicken coops in the dry Argentine Chaco (Vázquez-Prokopec et al. 2006), including fertilized females (Abrahan et al. 2011). Therefore, active dispersal of triatomine bugs (by flight or walking) may account for similar wing shape patterns in bugs from geographically close sites. The similarities found in bug populations from sites located beyond the assumed dispersal distance of $T$. infestans may be explained by: 1) revisiting the maximum flight range of T.infestans, which is based on very limited evidence; 2) cumulative dispersal over successive flight events away from the source site. In our study area, house compounds tend to have a continuous distribution that would facilitate dispersal between adjacent villages (i.e., communities are not defined as distinct groups of houses separated from the next community), and 3) passive dispersal. All of these mechanisms would lead to substantial gene flow among distant bug populations and, in consequence, lack of wing shape differences (Dujardin 2011). The hypothesis of isolation to explain shape differences should also consider habitat differences (Dujardin 2011). Although environmental data were not included in these analyses, to some extent its effects were included indirectly through ecotope and individual-site characteristics. Further analyses including environmental and ecological variables may shed light on their separate contribution. However, in the current study spatially close collection sites were grouped together despite differences in the type of ecotope. Further research on the dispersal of $T$. infestans under field conditions is essential for a better understanding of bug population dynamics and informing vector control programs on the degree of isolation among bug populations. Whenever there is frequent exchange of individuals between populations, at least one of them could act as a source of individuals that may reinfest treated houses and villages, thus jeopardizing insecticide-based interventions.

Our second focus was on wing size variations using geometric morphometry. The observed sexual dimorphism in wing CS and body $\mathrm{L}$ is in good agreement with the general pattern within Triatominae, with females being on average larger than males (Lent and Wygodzinsky 1979). Body L and wing CS were closely correlated, as expected, because wing size is known to be proportional to the individual's size in insects (Bursell 1960) and wing geometric morphometry uses CS as an estimator of wing size. However, no significant association was found between body $\mathrm{L}$ and wing or head CS in $T$. infestans collected in the dry Argentine Chaco (Hernández et al. 2010). Because body size is known to be influenced by numerous factors, the relationship between wing size and body size needs to be investigated further.

Our results show that domestic males of $T$. infestans were significantly smaller than peridomestic males collected from either open or closed structures, whereas no CS differences were detected between females from different ecotopes, perhaps because of their greater flight range. These results are consistent with previous findings for $T$. infestans in the dry Argentine Chaco during the same season: 1) males from domiciles and/or storerooms had significantly smaller wing CS than males from open peridomestic structures (pig corrals) (Schachter-Broide et al. 2009); 2) males and nymphs (but not females) from chicken coops had larger head and wing CS than bugs collected in goat corrals (Hernández et al. 2010). Some issues that limit comparisons are that most goat and pig corrals in our study area were not infested probably because of construction or host management characteristics 
(Gurevitz et al. 2011), whereas previous studies included few or no bugs from domestic structures (Schachter-Broide et al. 2004, 2009; Hernández et al. 2010). Moreover, wing CS at given ecotopes was observed to vary seasonally elsewhere in the Chaco region, probably because of variations in microclimatic conditions, bug dispersal dynamics, and vector-tohost abundance (Schachter-Broide et al. 2009). Several variables affect bug nutritional status and in consequence, bug development and dispersal. In our study, most domestic bugs fed on humans (R.E.G., unpublished data) and were smaller in L and CS than their peridomestic conspecifics blood-fed on other animal hosts during spring. Such smaller specimens may be attributed to several processes: 1) mud-and-thatch human habitations (domiciles) dampen outdoor temperatures and provide better conditions and extended activity periods for domestic T. infestans, especially during the cold season (Vázquez-Prokopec et al. 2002); 2) bloodmeal size and feeding frequency may increase with greater host availability in domiciles in comparison with some peridomestic habitats (Ceballos et al. 2005); 3) the relative density of bugs (Caro-Riaño et al. 2009), and 4) size-biased adult bug dispersal (Schachter-Broide et al. 2009). In addition, adult developmental times of human-fed bugs were shorter than when fed on other experimental hosts (Lima Gómes et al. 1990). Theoretical considerations support that smaller bugs would survive better under laboratory conditions or in human dwellings where host availability is less restricted, whereas natural selection would favor larger phenotypes in sylvatic habitats to withstand temporary food shortages (Dujardin et al. 1997b), such as those that occur in goat or pig corrals (Ceballos et al. 2005). However, some studies showed a negative correlation or no correlation at all between insect size and developmental time, arguing against the generalized assumption of a trade-off between those variables (Klingenberg and Spence 1997, Caro-Riaño et al. 2009).

The population dynamics and epidemiological consequences (in terms of acquiring or transmitting $T$. cruzi parasites) of smaller body or wing size have not been investigated in domestic species of Triatominae. This subject may have important implications because most $T$. cruzi infections are concentrated in domestic $T$. infestans in human habitations, more so in its adult stage (e.g., Gürtler et al. 1998).

Our study has several strengths and limitations. Among the former: 1) we considered bug collection sites as the minimum unit of analysis, rather than using the house compound or the community, because previous studies showed that individual collection sites represented the discrete unit where shape differentiation took place (Schachter-Broide et al. 2004).

Therefore, we grouped insects that most likely had developed under very similar conditions (environmental and parental);2) the numbers of bugs and bug populations analyzed at a fine spatial scale were substantially larger than in former studies, and 3) sample sizes'

distribution among collection sites was balanced to avoid statistical biases. Some limitations that we noted are: 1) wing coordinates were obtained by digitalizing them only once. However, two digitalizations performed on a random sample of 20 wings by the same person (M.S.G.) achieved an average repeatibility of the first 10 RWs of $0.86(0.63-0.99)$; 2) collection sites were assumed to be the place where the insects developed, and 3) sample sizes did not reach the required number of bugs per group relative to the number of shape variables included in the analyses. This issue was addressed by reducing the number of variables to reach a more balanced relationship and therefore would not affect the qualitative outcomes substantially.

Our results show the potential of wing geometric morphometry in population structuring studies at a spatial scale of a few kilometers. This may be helpful to assess the putative origin of reinfestant bugs after residual spraying with insecticides and guide vector control operations. 


\section{Acknowledgments}

We are grateful to Jorge Nasir, the Chagas Control Program of Chaco and the National Vector Control Coordination for support in field operations. Leonardo Ceballos, Gustavo Enriquez, Julián Alvarado-Otegui, and Paula Ordoñez-Krasnowski provided field and laboratory assistance. Ana Laura Carbajal de la Fuente and Romina Piccinali for critical revision of the manuscript. Fundación Mundo Sano provided extensive support locally through an operation center. This study was supported by awards from the UNICEF/UNDP/World Bank/WHO Special Programme for Research and Training in Tropical Diseases (TDR), International Development Research Center, and University of Buenos Aires to R.E.G., and National Institutes of Health/National Science Foundation Ecology of Infectious Disease program award R01 TW05836 funded by the Fogarty International Center and the National Institute of Environmental Health Sciences to U.K. and R.E.G. M.S.G. and J.M.G. were supported by scholarships from Consejo Nacional de Investigaciones Científicas y Técnicas de Argentina (CONICET). R.E.G. is a member of CONICET Researcher's Career. The contents of this study are solely the responsibility of the authors and do not necessarily represent the official view of Centre National de Recherche Scientifique, Institutes de Recherches pour le Développment, or National Institutes of Health.

\section{References Cited}

Abrahan L, Hernández L, Gorla D, Catalá S. Phenotypic diversity of Triatoma infestans at the microgeographic level in the Gran Chaco of Argentina and the Andean valleys of Bolivia. J Med Entomol. 2008; 45:660-666. [PubMed: 18714865]

Abrahan LB, Gorla DE, Catalá SS. Dispersal of Triatoma infestansand other Triatominae species in the arid Chaco of Argentina: flying, walking or passive carriage? The importance of walking females. Mem Inst Oswaldo Cruz. 2011; 106:232-239. [PubMed: 21537686]

Bargues MD, Klisiowicz DR, Panzera F, Noireau F, Marcilla A, Perez R, Rojas MG, O'Connor JE, Gonzalez-Candelas F, Galvão C, et al. Origin and phylogeography of the Chagas disease main vector Triatoma infestans based on nuclear rDNA sequences and genome size. Inf Gen Evol. 2006; 6:46-62.

Bohonak AJ. IBD (Isolation By Distance): a program for analyses of isolation by distance. J Hered. 2002; 93:153-154. [PubMed: 12140277]

Bookstein, FL. In: Rohlf, FJ.; Bookstein, FL., editors. Introduction to methods for landmark data; Proceedings of the Michigan Morphometrics Workshop, The University of Michigan Museum of Zoology, Special Publication No. 2; Ann Arbor, MI. 1990. p. 216-225.

Bouyer J, Raver S, Dujardin JP, de Meeus T, Vial L, Thévenon S, Guerrini L, Sidibé I, Solano P. Population structure of Glossina palpalis gambiensis (Diptera: Glossinidae) according to landscape fragmentation in the Mouhoun River, Burkina Faso. J Med Entomol. 2007; 44:788-795. [PubMed: 17915509]

Brenière SF, Bosseno MF, Vargas F, Yaksic N, Noireau F, Noel S, Dujardin JP, Tibayrenc M. Smallness of the panmictic unit of Triatoma infestans (Hemiptera: Reduviidae). J Med Entomol. 1998; 35:911-917. [PubMed: 9835679]

Brochero H, Li C, Wilkerson R, Conn JE, Ruiz-García M. Genetic structure of Anopheles (Nyssorhynchus) marajoara (Diptera: Culicidae) in Colombia. Am J Trop Med Hyg. 2010; 83:585595. [PubMed: 20810825]

Bursell E. The measurement of size in tsetse flies (Glossina). Bull Entomol Res. 1960; 51:33-37.

Camara M, Caro-Riaño H, Ravel S, Dujardin JP, Hervouet JP, deMeeüs T, Kagbadouno MS, Bouyer J, Solano P. Genetic and morphometric evidence for population isolation of Glossina palpalis gambiensis (Diptera: Glossinidae) on the Loos Islands, Guinea. J Med Entomol. 2006; 43:853860. [PubMed: 17017219]

Caro-Riaño H, Jaramillo N, Dujardin JP. Growth changes in Rhodnius pallescens under simulated domestic and sylvatic conditions. Inf Gen Evol. 2009; 9:162-168.

Ceballos LA, Vazquez-Prokopec GM, Cecere MC, Marcet PL, Gürtler RE. Feeding rates, nutritional status and flight dispersal potential of peridomestic populations of Triatoma infestans in rural northwestern Argentina. Acta Trop. 2005; 95:149-159. [PubMed: 15993834]

Cecere MC, Vazquez-Prokopec GM, Gürtler RE, Kitron U. Reinfestation sources for Chagas disease vector, Triatoma infestans, Argentina. Emerg Inf Dis. 2006; 12:1096-1102. 
de Queiroz Balbino V, Coutinho-Abreu IV, Sonoda IV, Almeida Melo M, de Andrade PP, Fonseca de Castro JA, Rebelo JM, Santos Carvalho SM, Ramalho-Ortigao M. Genetic structure of natural populations of the sand fly Lutzomyia longipalpis (Diptera: Psychodidae) from the Brazilian northeastern region. Acta Trop. 2006; 98:15-24. [PubMed: 16480941]

Dias JCP, Silveira AC, Schofield CJ. The impact of Chagas disease control in Latin America. A review. Mem Inst Oswaldo Cruz. 2002; 97:603-612. [PubMed: 12219120]

Dujardin, JP. Modern morphometrics of medically important insects. In: Tibayrenc, M., editor. Genetics and evolution of infectious diseases. Vol. 16. Elsevier Insights; London, United Kingdom: 2011. p. 474-501.

Dujardin, JP.; Slice, D. Geometric morphometrics. Contributions to medical entomology. In: Tibayrenc, M., editor. Encyclopedia of infectious diseases. Modern methodologies. Vol. 25. Wiley \& Sons; Hoboken, NJ: 2007. p. 435-447.

Dujardin JP, Tibayrenc M, Venegas E, Maldonado L, Desjeux P, Ayala FJ. Isozyme evidence of lack of speciation between wild and domestic Triatoma infestans (Heteroptera: Reduviidae) in Bolivia. J Med Entomol. 1987; 24:40-45. [PubMed: 3546693]

Dujardin JP, Bermúdez H, Schofield CJ. The use of morphometrics in entomological surveillance of sylvatic foci of Triatoma infestansin Bolivia. Acta Trop. 1997a; 66:145-153. [PubMed: 9210965]

Dujardin JP, Bermúdez H, Casini C, Schofield CJ, Tibayrenc M. Metric differences between sylvatic and domestic Triatoma infestans (Hemiptera: Reduviidae) in Bolivia. J Med Entomol. 1997b; 34:544-551. [PubMed: 9379460]

Dujardin JP, Schofield CJ, Tibayrenc M. Population structure of Andean Triatoma infestans: allozyme frequencies and their epidemiological relevance. Med Vet Entomol. 1998; 12:20-29. [PubMed: 9513935]

Dujardin JP, Le Pont F, Baylac M. Geographical versus interspecific differentiation of sand flies (Diptera: Psychodidae): a landmark data analysis. Bull Entomol Res. 2003; 93:87-90. [PubMed: 12593686]

Dujardin JP, Beard CB, Ryckman R. The relevance of wing geometry in entomological surveillance of Triatominae, vectors of Chagas disease. Inf Gen Evol. 2007; 7:161-167.

Dumonteil E, Tripet F, Ramírez-Sierra MJ, Payet V, Lanzaro G, Menu F. Assessment of Triatoma dimidiata dispersal in the Yucatán peninsula of Mexico by morphometry and microsatellite markers. Am J Trop Med Hyg. 2007; 79:930-937. [PubMed: 17488918]

Felsenstein, J. PHYLIP (Phylogeny Inference Package) version 3.6. Distributed by the author. Department of Genome Sciences, University of Washington; Seattle, WA: 2005.

Good, P. Permutation tests: a practical guide to resampling methods for testing hypotheses. Springer; New York: 2000.

Gorla DE, Porcasi X, Hrellac H, Catalá S. Spatial stratification of house infestation by Triatoma infestans in La Rioja, Argentina. Am J Trop Med Hyg. 2009; 80:405-409. [PubMed: 19270290]

Gumiel M, Catalá S, Noireau F, Rojas de Arias A, García A, Dujardin JP. Wing geometry in Triatoma infestans and T. melanosoma. Syst Entomol. 2003; 28:1-7.

Gurevitz JM, Ceballos LA, Kitron U, Gürtler RE. Flight initiation of Triatoma infestans (Hemiptera: Reduviidae) under natural climatic conditions. J Med Entomol. 2006; 43:143-150. [PubMed: 16619592]

Gurevitz JM, Kitron U, Gürtler RE. Flight muscle dimorphism and heterogeneity in flight initiation of field-collected Triatoma infestans (Hemiptera: Reduviidae). J Med Entomol. 2007; 44:186-191. [PubMed: 17427685]

Gurevitz JM, Ceballos LA, Gaspe MS, Alvarado-Otegui JA, Enriquez GF, Kitron U, Gürtler RE. Factors affecting infestation by Triatoma infestans in a rural area of the humid Chaco in Argentina: a multi-model inference approach. PLoS Negl Trop Dis. 2011; 5:e1365. [PubMed: 22039559]

Gürtler RE, Cohen JE, Cecere MC, Chuit R, Segura EL. Influence of humans and domestic animals on the household prevalence of Trypanosoma cruzi in Triatoma infestans populations in northwest Argentina. Am J Trop Med Hyg. 1998; 58:748-758. [PubMed: 9660458]

Gürtler RE, Canale DM, Spillman C, Stariolo R, Salomon DO, Blanco S. Effectiveness of residual spraying of peridomestic ecotopes with deltamethrin and permethrin on Triatoma infestans in rural 
western Argentina: a district-wide randomized trial. Bull WHO. 2004; 82:196-205. [PubMed: 15112008]

Gürtler RE, Kitron U, Cecere MC, Segura EL, Cohen JE. Sustainable vector control and management of Chagas disease in the Gran Chaco, Argentina. Proc Natl Acad Sci USA. 2007; 104:1619416199. [PubMed: 17913895]

Hernández ML, Abraham LB, Dujardin JP, Gorla DE, Catalá SS. Phenotypic variability and population structure of peridomestic Triatoma infestans in rural areas of the arid Chaco (western Argentina): spatial influence of macro- and microhabitats. Vector-Borne Zoon Dis. 2010; 11:503513.

Klingenberg CP, Spence JR. On the role of body size for life-history evolution. Ecol Entomol. 1997; 22:55-68.

Lehane MJ, Schofield CJ. Flight initiation in Triatoma infestans (Klug) populations (Reduviidae: Triatominae). Bull Entomol Res. 1982; 72:497-510.

Lent H, Wygodzinsky P. Revision of the Triatominae (Hemiptera: Reduviidae), and their significance as vectors of Chagas disease. Bull Am Mus Nat His. 1979; 163:123-520.

Lima Gómes JEP, Azambuja P, García ES. Comparative studies on the growth and reproductive performances of Rhodnius prolixus reared on different blood sources. Mem Inst Oswaldo Cruz. 1990; 85:299-304. [PubMed: 2134703]

Marcet PL, Mora MS, Cutrera AP, Jones L, Gürtler RE, Kitron U, Dotson EM. Genetic structure of Triatoma infestans populations in rural villages of Santiago del Estero, northern Argentina. Inf Gen Evol. 2008; 8:835-846.

Monroy C, Bustamante DM, Rodas A, Rosales R, Mejía M, Tabaru Y. Geographic distribution and morphometric differentiation of Triatoma nitida Usinger 1939 (Hemiptera: Reduviidae: Triatominae) in Guatemala. Mem Inst Oswaldo Cruz. 2003; 98:37-43. [PubMed: 12700860]

Pérez de Rosas AR, Segura EL, García BA. Microsatellite analysis of genetic structure in natural Triatoma infestans (Hemiptera:Reduviidae) populations from Argentina: its implication in assessing the effectiveness of Chagas' disease vector control programmes. Mol Ecol. 2007; 16:1401-1412. [PubMed: 17391265]

Pérez de Rosas AR, Segura EL, Fichera L, García BA. Macrogeographic and microgeographic genetic structure of the Chagas' disease vector Triatoma infestans (Hemiptera: Reduviidae) from Catamarca, Argentina. Genetica. 2008; 133:247-260. [PubMed: 17885811]

Piccinali RV, Marcet PL, Noireau F, Kitron U, Gürtler RE, Dotson EM. Molecular population genetics and phylogeography of the Chagas disease vector Triatoma infestans in South America. J Med Entomol. 2009; 40:796-809. [PubMed: 19645282]

Pizarro JC, Gilligan LM, Stevens L. Micro-satellites reveal a high population structure in Triatoma infestans from Chuquisaca, Bolivia. PLoS Negl Trop Dis. 2008; 2:e202. [PubMed: 18365033]

Richer W, Kegne P, Rojas Cortez M, Perrineua MM, Cohuet A, Fontenille D, Noireau F. Active dispersal by wild Triatoma infestans in the Bolivian Andes. Trop Med Int Health. 2007; 12:759 764. [PubMed: 17550473]

Rohlf, FJ. Morphometric spaces, shape components and the effects of linear transformations. In: Marcus, LF.; Corti, M.; Loy, A.; Naylor, GJP.; Slice, D., editors. Advances in morphometrics NATO ASI, series A, life sciences. Plenum Publication; New York: 1996. p. 117-129.

Scarpassa VM, Cardoza TB, Cardoso RP Junior. Population genetics and phylogeography of Aedes aegypti (Diptera: Culicidae) from Brazil. Am J Trop Med Hyg. 2008; 78:895-903. [PubMed: 18541766]

Schachter-Broide J, Dujardin JP, Kitron U, Gürtler RE. Spatial structuring of Triatoma infestans (Hemiptera, Reduviidae) populations from northwestern Argentina using wing geometric morphometry. J Med Entomol. 2004; 41:643-649. [PubMed: 15311455]

Schachter-Broide J, Gürtler RE, Kitron U, Dujardin JP. Temporal variations of wing size and shape of Triatoma infestans (Hemiptera:Reduviidae) populations from northwestern Argentina using geometric morphometry. J Med Entomol. 2009; 46:994-1000. [PubMed: 19769028]

Schofield CJ, Lehane MJ, McEwen P, Catalá SS, Gorla DE. Dispersive flight by Triatoma infestans under natural climatic conditions in Argentina. Med Vet Entomol. 1992; 6:51-56. [PubMed: 1600228] 
Schofield CJ, Jannin J, Salvatella R. The future of Chagas disease control. Trends Parasitol. 2006; 22:583-588. [PubMed: 17049308]

Schweigmann N, Valvé S, Muscio O, Ghillini M, Alberti A, Wisniveski-Colli C. Dispersal flight by Triatoma infestans in an arid region of Argentina. Med Vet Entomol. 1988; 2:401-404. [PubMed: 2980200]

Solano P, Kaba D, Ravel S, Dyer NA, Sall B, Vreysen MJB, Seck MT, Darbyshir H, Gardes L, Donnelly MJ, De Meeus T, Bouyer J. Population genetics as a tool to select tsetse control strategies: Suppression or eradication of Glossina palpalis gambiensis in the Niayes of Senegal. PloS Negl Trop Dis. 2010; 4:e692. [PubMed: 20520795]

StatCorp. Stata statistical software, Release 10.1. StataCorp; College Station, TX: 2008.

Vázquez-Prockopec GM, Ceballos LA, Cecere MC, Gürtler RE. Seasonal variations of microclimatic conditions in domestic and peridomestic habitats of Triatoma infestans (Hemiptera: Reduviidae) in rural northwestern Argentina. J Med Entomol. 2002; 41:614-621.

Vázquez-Prockopec GM, Ceballos LA, Marcet PL, Cecere MC, Cardinal MV, Kitron U, Gürtler RE. Seasonal variations in active dispersal of natural populations of Triatoma infestans in rural northwestern Argentina. Med Vet Entomol. 2006; 20:1-6. [PubMed: 16608485]

Ward JP, Baker PS. The tethered flight performance of a laboratory population of Triatoma infestans (Klug) (Hemiptera: Reduviidae). Bull Entomol Res. 1982; 72:17-28.

(WHO) World Health Organization. Reporte sobre la enfermedad de Chagas. 2007. TDR/SWG/09

zu Dohna H, Cecere MC, Gürtler RE, Kitron U, Cohen JE. Spatial re-establishment dynamics of local populations of vector of Chagas disease. PLoS Negl Trop Dis. 2009; 3:1-11. 


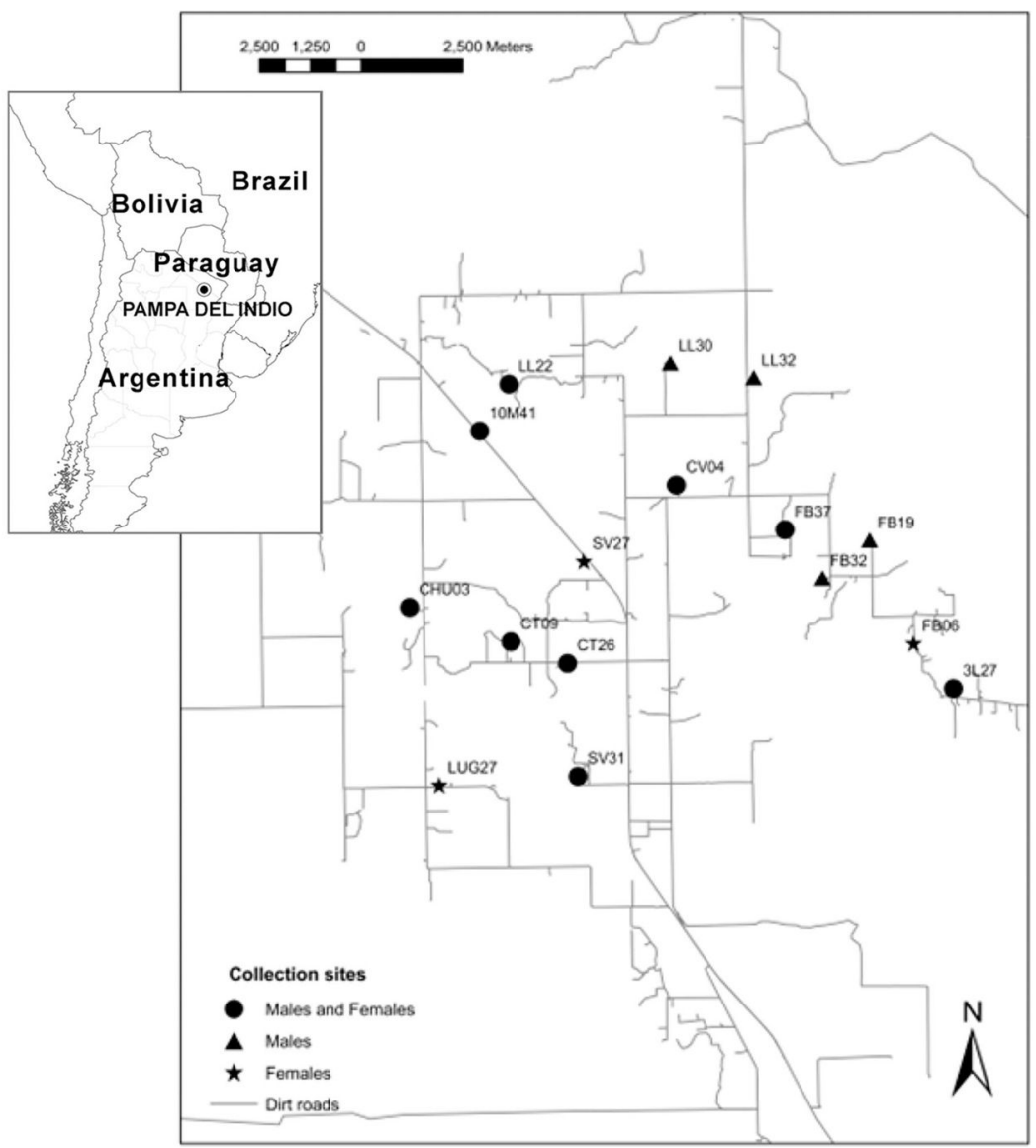

Fig. 1.

Map of the study area in Pampa del Indio, Chaco, Argentina, showing the collection sites included in the analysis. 

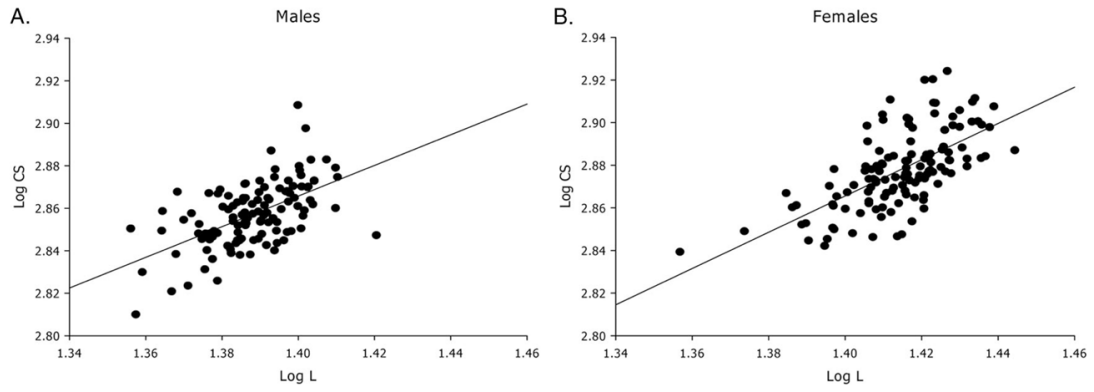

Fig. 2.

Linear regression analysis of log-total body L and log-wing CS in T. infestans from Pampa del Indio collected at baseline in 2007. (A) Males $(n=120)$, (B) females $(n=128)$. 
A.

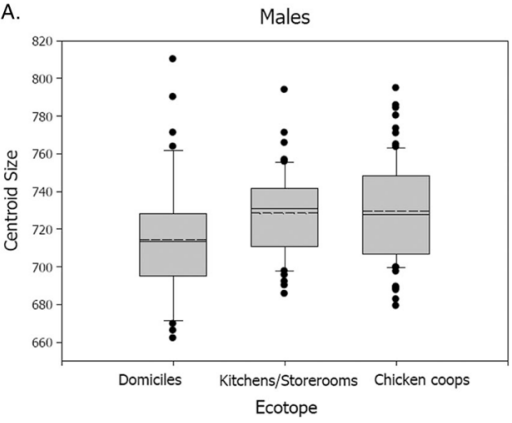

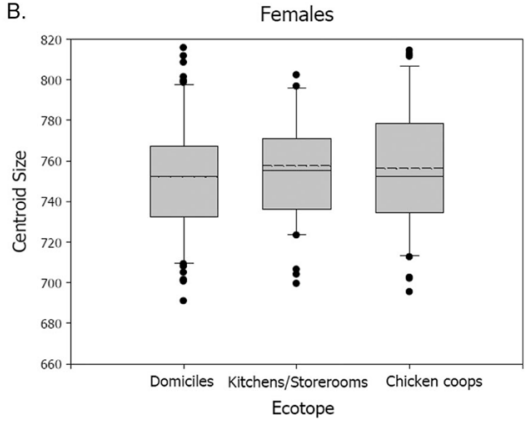

Fig. 3.

Sex-specific variations of $T$. infestans $\mathrm{CS}$ among domiciles, kitchens or storerooms, and chicken coops. Box plots show the median (solid line), mean (dashed line), first and third quartiles. Whiskers indicate the 90th and 10th percentiles. Dots beyond whiskers are potential outliers. (A) Males ( $n=42,50,80$, respectively), (B) females $(n=62,41,46$, respectively). 


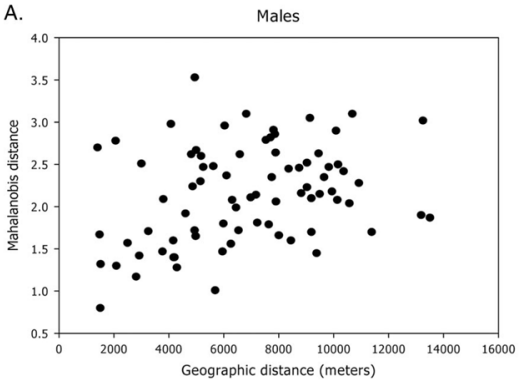

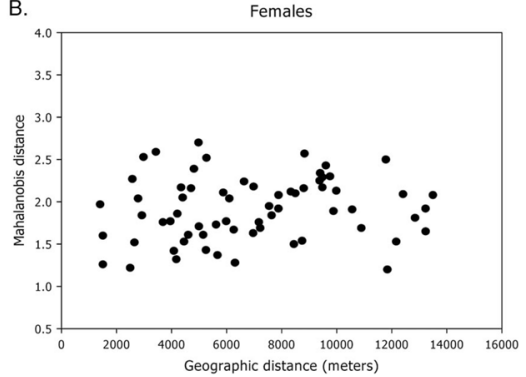

Fig. 4.

Linear regression analysis of Mahalanobis distances of male and female wings on geographic distance between pairs of collection sites of T. infestans. (A) Males $(n=172)$, (B) females $(n=149)$. 

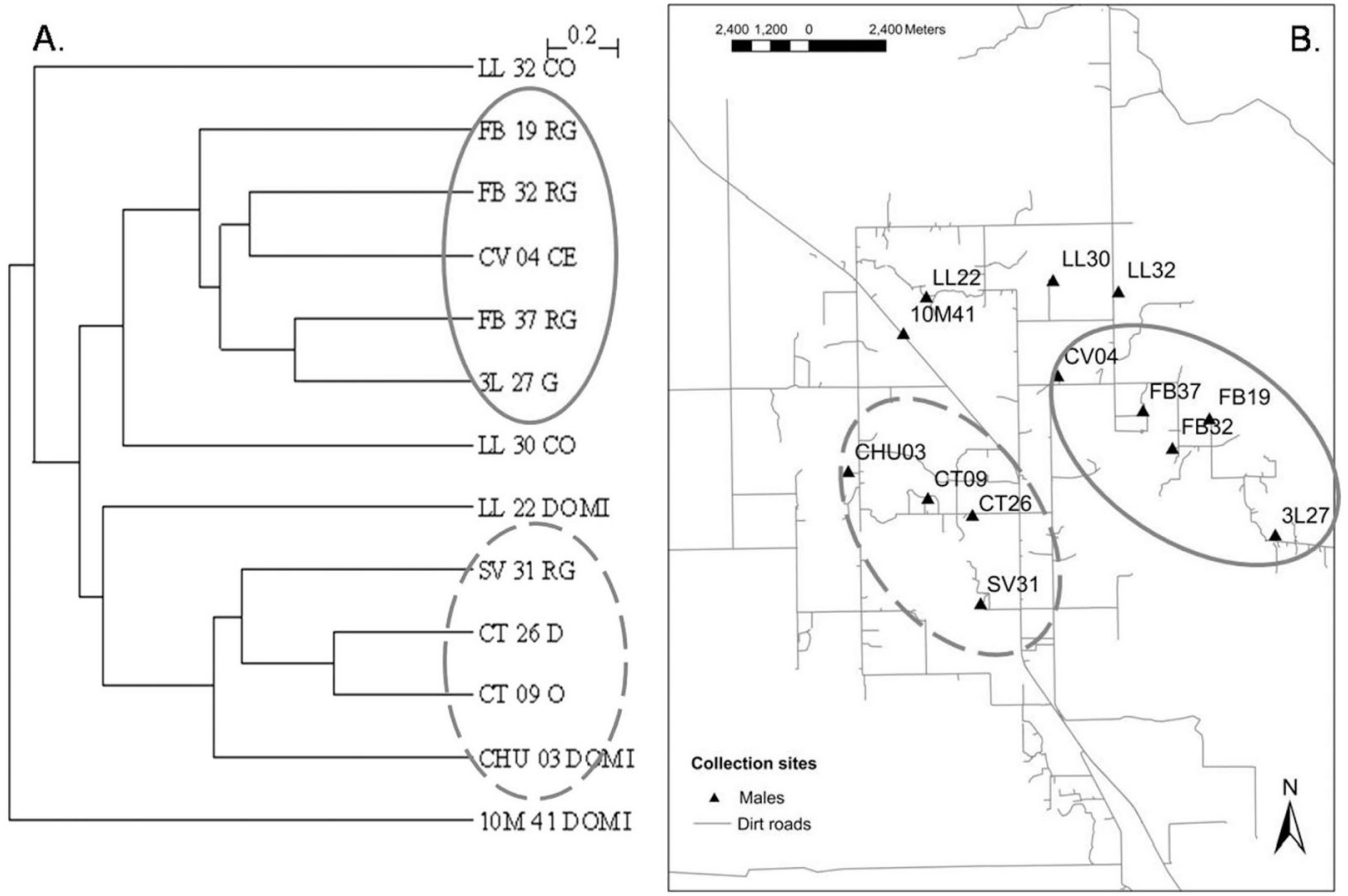

Fig. 5.

Males. (A) Unweighted pair-grouped method with arithmetic average dendrogram derived from Mahalanobis distances between collection sites. (B) Map of the houses included in the analyses. The two circles correspond to collection sites grouped together and presented no significant differences in Mahalanobis distances $(P>0.001)$. The first two letters are the name of the community; the numbers after community names are house numbers; DOMI, domicile; CO, D, O, are kitchen or storeroom; G, RG, CE are sites associated with chickens. 

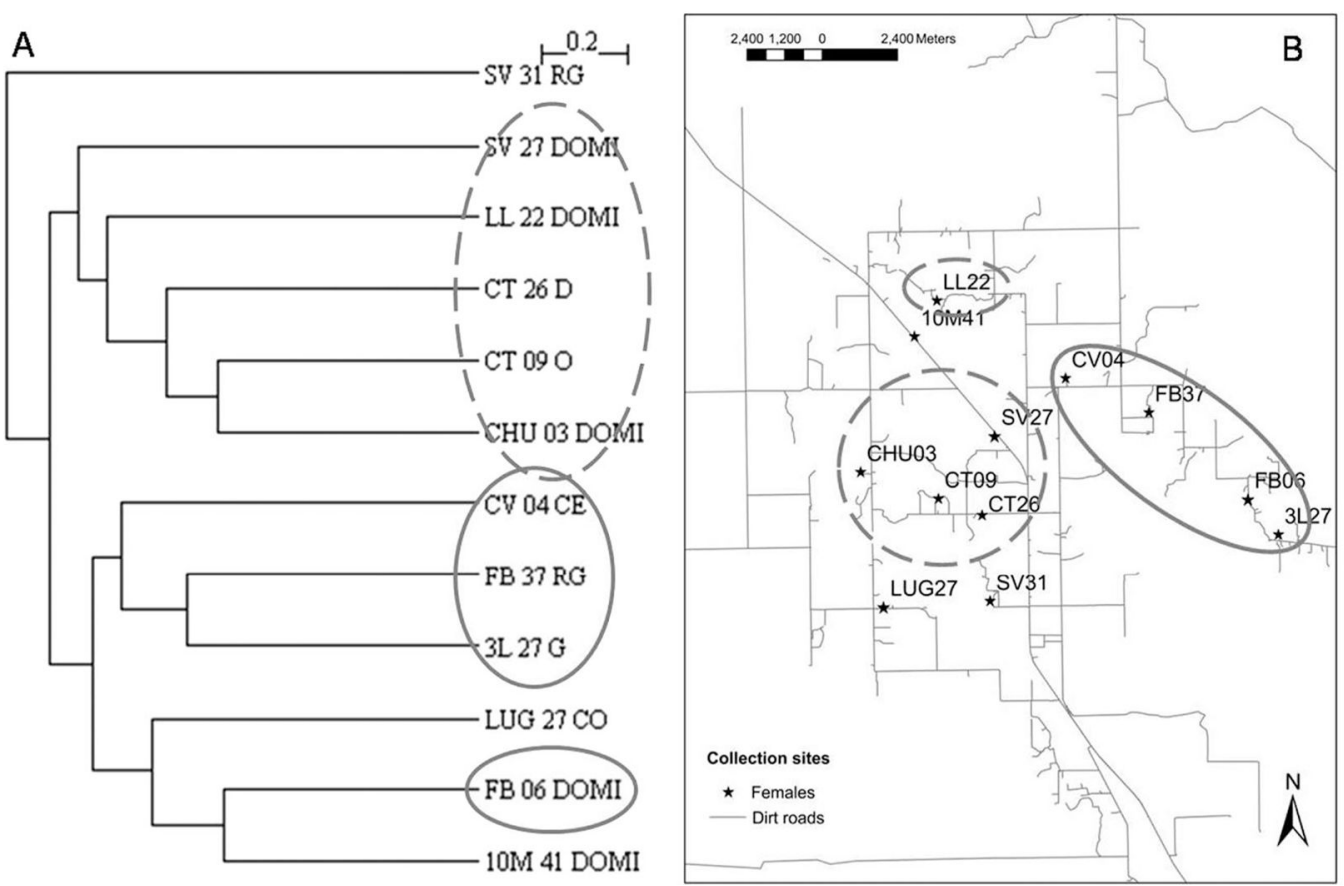

Fig. 6.

Females. (A) Unweighted pair-grouped method with arithmetic average dendrogram derived from Mahalanobis distances between collection sites. (B) Map of the study houses. The circles correspond to the groups that coincide in both figures. The first two letters is the name of the community; the numbers after community names are house numbers; DOMI, domicile; CO, D, O, are kitchen or storeroom; G, RG, CE, are sites associated with chickens. 